\title{
HARMONISATON INITIATIVES OF COPERNICUS DATA QUALITY CONTROL
}

\author{
Fabio D. Vescovi ${ }^{\mathrm{a}}$, Thomas Lankester ${ }^{\mathrm{a}}$, Emma Coleman $^{\mathrm{a}}$, Giuseppe Ottavianelli ${ }^{\mathrm{b}}$ \\ a Airbus Defence and Space, Europa House, The Crescent, Farnborough, GU14 0NL - UK - EOData_QC@Copernicus.esa.int \\ ${ }^{\mathrm{b}}$ European Space Agency, ESA/ESRIN Via Galileo Galilei Casella Postale 6400044 Frascati (Roma) - Italy
}

KEY WORDS: Copernicus, Data Harmonisation, Quality Control.

\begin{abstract}
:
The Copernicus Space Component Data Access system (CSCDA) incorporates data contributions from a wide range of satellite missions. Through EO data handling and distribution, CSCDA serves a set of Copernicus Services related to Land, Marine and Atmosphere Monitoring, Emergency Management and Security and Climate Change.

The quality of the delivered EO products is the responsibility of each contributing mission, and the Copernicus data Quality Control (CQC) service supports and complements such data quality control activities. The mission of the CQC is to provide a service of quality assessment on the provided imagery, to support the investigation related to product quality anomalies, and to guarantee harmonisation and traceability of the quality information.

In terms of product quality control, the CQC carries out analysis of representative sample products for each contributing mission as well as coordinating data quality investigation related to issues found or raised by Copernicus users. Results from the product analysis are systematically collected and the derived quality reports stored in a searchable database.

The CQC service can be seen as a privileged focal point with unique comparison capacities over the data providers. The comparison among products from different missions suggests the need for a strong, common effort of harmonisation. Technical terms, definitions, metadata, file formats, processing levels, algorithms, cal/val procedures etc. are far from being homogeneous, and this may generate inconsistencies and confusion among users of EO data.

The CSCDA CQC team plays a significant role in promoting harmonisation initiatives across the numerous contributing missions, so that a common effort can achieve optimal complementarity and compatibility among the EO data from multiple data providers. This effort is done in coordination with important initiatives already working towards these goals (e.g. INSPIRE directive, CEOS initiatives, OGC standards, QA4EO etc.).

This paper describes the main actions being undertaken by CQC to encourage harmonisation among space-based EO systems currently in service.
\end{abstract}

\section{INTRODUCTION}

\subsection{State of the Art}

As there is an increased use of digital maps and spatial data within the user community, clear definitions of contents, structures, data processing and functions are increasingly needed. These definitions are expected to build a common language, uniform among missions and understood in an unambiguous way by users. The need for harmonising and standardising such common language is currently only partially covered by international standards (e.g. ISO, OGC, etc.). Depending on contextual use and external factors, these definitions can vary in some cases also significantly, thus causing confusion and eventually loss of interest among the users towards the use of advanced geographic technologies and EO data (Ziegler and Dittrich, 2004). In view of this risk, it is generally agreed that there is a need for harmonisation in the Earth Observation industrial and scientific sectors and in the geographical information context at large.

Geodata harmonisation implies and means the possibility to combine data from heterogeneous sources into seamlessly integrated, consistent and unambiguous information products, in an easy and repeatable way, adapted to the end-user's requirements and context. (Schulze Althoff and Giger 2009)

This is essential not only for data integration and/or exchange between systems but also when migrating data from different sources across boundaries within EU countries and outside Europe (Giger and Schulze Althoff, 2012).Inconsistencies between spatial data are present across many areas, causing divergence in data storage and functions. Heterogeneity is present within the following aspects:

- Data format (Ziegler and Dittrich, 2004)

- File data/conceptual model: structure and constraints

- Metadata model (OGC, 2010)

- Data collection procedures

- Spatial reference system / projections

- Nomenclature, classification, taxonomy, terminology, thesaurus, ontology (Tikunov et al. 2008)

- Zooming functionalities, scale, amount of detail displayed (A. Kuijper, 2009)

- Portrayal (legend/classification, style)

- Parameters, formulas, algorithms and relevant processing functions

A number of initiatives have already been launched to tackle one or more of the above-mentioned aspects. The following paragraphs summarise the most relevant of these.

The Open Geospatial Consortium (OGC) is composed of more than 25 Technical Committees to address interoperability in particular technology and application domains. Standards and best practices are developed to enable diverse systems to "talk to each other." Any new initiative in the context of geodata services should be interoperable with the existing services codified by geospatial standardisation organisations, and in particular the (OGC) at international level (McKee 2001).

Digital Earth vision is a global initiative of the International Society for Digital Earth to construct a comprehensive virtual representation of the planet. The integration of services, tools and data (Grossneret al. 2008) envisages new perspectives aiming at harmonising the geo-information shared among users in Earth sciences, space sciences and information sciences to 
build better capacities of knowledge and management of our planet (Gore 1999).

At European level, the process to geo-information sharing and integration is led by the guidelines contained in the INSPIRE Directive of the European Union (Villa et al. 2012). The INSPIRE Directive consists of a regulation framework for European geodata aiming at enforcing the use of best practices and integrated interfaces for the benefit of users and enterprises. A rich body of online literature is already available on this topic (the Authors refer to the links quoted in the Bibliography under "INSPIRE online literature").

The Quality Assurance Framework for Earth Observation (QA4EO), endorsed by the Committee on Earth Observation Satellites (CEOS) as a contribution to facilitate the GEO vision for a Global Earth Observation System of Systems (GEOSS). QA4EO encompasses a framework and set of ten key guidelines, derived from best practices and with example templates included to aid implementation. Each GEO stakeholder community should be responsible for its own overall governance within the framework (GEO, 2010).

RISE was an FP6 project with the aim to produce methodologies and guidelines for the creation of geodata specifications consistent with the international and industrial standards. In such context Europe may meet its needs for a sustainable and interoperable functioning of GMES (now Copernicus) services within the INSPIRE principles. An outcome of the RISE project (Eriksson and Hartnor, 2006; Portele, 2006) was the provision of a general data harmonisation methodology that can be applied to spatial data, through the development of harmonised product specifications. Besides these proposed standards which can be considered now well-established, there are various areas where standardisation has not come very far yet or where there are multiple competing standards (Ziegler and Dittrich 2004). In addition, all those efforts in the field of geodata harmonisation approach have tackled only one harmonisation issue at a time (e.g. schema mapping, catalogue search services, language translation and ontology). The HUMBOLDT project delivered a framework that is both a theoretical one and a framework of software tools that can handle the harmonisation process as a whole, tackling multiple harmonisation issues as instances of the same overall harmonisation process (Villa et al. 2012). The project focused on the objective of enabling harmonisation instances which were not covered by existing standardised procedures (Villa et al. 2008).

Other projects dealt mainly with ontological issues, as for example the HarmonISA-project (Hall 2006) that aimed at developing a set of tools to semi-automatically integrate different land-use datasets through an expert-driven approach supported by the used and developed software such as ontology editors.

\subsection{Role of Copernicus Quality Control (CQC)}

In the frame of the Copernicus Space Component Data Access (CSCDA), where a range of satellite missions deliver products and services to Copernicus user community, the Copernicus Quality Control (CQC) service is responsible for the quality assessment of the data delivered by the contributing missions. The data quality of each single product delivered remains the responsibility of the contributing missions however.

This paper focus on one of the tasks assigned to the CQC called "Task 7 - Harmonisation": to suggest and eventually provide harmonisation to data, parameters, names and functionalities among the different satellite data providers (CCMEs).
The CQC mission can only be successfully accomplished by handling the various harmonisation issues as a whole and tackling them as instances of the same overall harmonisation process. In this context the CQC Team apply two approaches: a "holistic" approach and a standardisation approach.

1. "Holistic" approach. The CQC Team is aware that the different Copernicus components have constant interactions ongoing with one another. Ideally they should inter-operate in a harmonious fashion like the many organs of one body so that whatever modification is done on one part may affect all related parts. For example, if a new name of a certain product is required by the stakeholders to ease its understanding, the upstream processing chains which process, generate and archive that product must be accordingly modified. In turn, the downstream Copernicus user interface for searching, ordering and retrieving that product (typically based on WMS technologies) is impacted and this, in turn, cascades on the users' archive facilities, folders, naming conventions and eventually on the users' language used for the published literature and general communications. The need for harmonising this complex mix of human factors, IT infrastructures and dedicated software can be addressed only by means of a "holistic" approach which considers these complexities as a "whole", i.e. a complex unit composed of multiple elements inter-acting one another. Any action aiming at building a harmonious set of conventions (naming, standard processes, etc.) is unlikely to work on the overall complex Copernicus structure unless an appropriate study of the relevant end-to-end chain is carefully accomplished.

2. Standard approach. This approach takes advantage of the rich legacy of European and internationally acknowledged standards already created and well established. All CQC harmonisation initiatives will be inscribed in the frame of reference of initiatives (e.g. INSPIRE, OGC, QA4EO) as reported in the "State-of-the-Art" paragraph of this paper.

In the following paragraphs examples of harmonisation initiatives are presented for the following identified areas of inconsistencies among the CCMEs:

- Processing levels

- Cloud measures reported in metadata

- Acquisition Mode naming

- Definitions of acquisition angles

\section{PROCESSING LEVELS}

This harmonisation initiative deals with one of the most addressed issues of the users: the image processing levels are differently defined across CCMEs. The processing levels (in some cases called "Product Types") refer mostly to the series of geometric and radiometric corrections that the image undergoes from its native format to its downstream processes. This CQC initiative will deal only with geometric corrections involved (e.g. geolocation process, orthorectification, etc.) Three aspects are considered not consistent within the geometric processing levels: their naming convention (codes), the processing methods and the associated errors.

For example an image not yet processed for orthorectification may be defined as Non-ortho, Ortho-ready, Geo-referenced, etc. whereas an orthorectifed image can be defined as Ortho, Orthorectified, Orthocorrected, Geoprofessional, etc. Since methods, inputs and algorithms to perform an orthorectification process are different across CCMEs, the precision levels are accordingly different. Each geometric process should result in a 
geometric accuracy defined by the relevant precision error, which should be duly reported in the metadata. But this error can be reported as Root Mean Square (RMS) error (i.e. X and Y separately) and/or Directional Root Mean Square (DRMS) error (i.e. for one direction) and/or Circular Error (CE) or Planimetric Accuracy Measurement. Additionally the processing level code (e.g. L1R, L1B, etc.) is also heterogeneous across CCMEs products.

Table 1 summarizes all this across the CCMs. The various definitions of processing level codes, geometric correction

\begin{tabular}{|c|c|c|c|c|}
\hline Ortho & Mission & $\begin{array}{l}\text { Processing } \\
\text { Level Code }\end{array}$ & Process & $\begin{array}{l}\text { Error in } \\
\text { Metadata }\end{array}$ \\
\hline \multirow{14}{*}{ 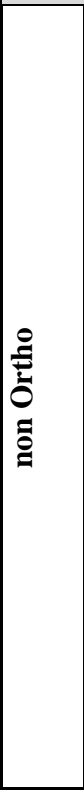 } & $\begin{array}{l}\text { Deimos-1, DMC } \\
\text { constellation }\end{array}$ & L1R & Band registered product derived from the $\mathrm{L} 0 \mathrm{R}$ product & $\begin{array}{l}\text { RMS in X Y. } \\
\text { CE90 and CE96 }\end{array}$ \\
\hline & \multirow{2}{*}{ IR05 } & OB & Browse product (of the acquired raw data) & \multirow{6}{*}{ no } \\
\hline & & 10 & $\begin{array}{l}\text { Ortho kit (monoscopic, System corrected product supplied with } \\
\text { RPC file.) }\end{array}$ & \\
\hline & \multirow{2}{*}{ IRS-P6 Resourcesat-1 } & OB & Browse product (of the acquired raw data) & \\
\hline & & 10 & $\begin{array}{l}\text { Ortho kit (monoscopic, System corrected product supplied with } \\
\text { RPC file.) }\end{array}$ & \\
\hline & \multirow[b]{2}{*}{ IRS-R2 Resourcesat-2 } & OB & Browse product (of the acquired raw data) & \\
\hline & & 10 & $\begin{array}{l}\text { Ortho kit (monoscopic, System corrected product supplied with } \\
\text { RPC file.) }\end{array}$ & \\
\hline & GeoEye, IKONOS & GE & Geo product (--> radiometrically corrected map oriented image) & no \\
\hline & \multirow{2}{*}{ QuickBird, WorldView1/2 } & $\mathrm{SO}$ & $\begin{array}{l}\text { Standard Ortho-Ready (--> no topographic corrections i.e. suitable } \\
\text { for orthorectification) }\end{array}$ & \multirow[b]{2}{*}{ no } \\
\hline & & SD & $\begin{array}{l}\text { Standard (--> georeferenced }=\text { radiometric and geometric } \\
\text { correction) product }\end{array}$ & \\
\hline & RapidEye & $1 \mathrm{~B}$ & Radiometric corrected & no \\
\hline & Pléiades 1A/B & $1 \mathrm{~A}$ or SEN & Raw product (Ortho ready) & no \\
\hline & SPOT-5/6/7, & $1 \mathrm{~A}$ & Raw product (Ortho ready) & no \\
\hline & SPOT5 & $2 \mathrm{~A}$ & Projected product without ground reference points & no \\
\hline \multirow{18}{*}{ 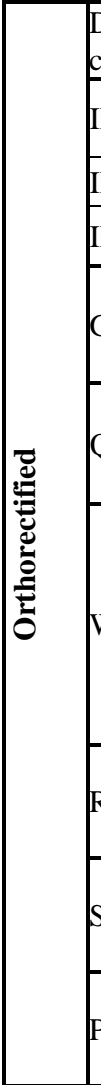 } & $\begin{array}{l}\text { Deimos-1, DMC } \\
\text { constellation }\end{array}$ & L1T & $\begin{array}{l}\text { Orthorectified product derived from the L1R product using } \\
\text { manually collected GCPs from Landsat ETM+. }\end{array}$ & $\begin{array}{l}\text { RMS in X and Y. } \\
\text { CE90 and CE96 }\end{array}$ \\
\hline & IRS-P5 Cartosat-1 & 30 & $\begin{array}{l}\text { Process based on RPCs. GCPs derived from image matching } \\
\text { between IRS scene and reference image. Generally the SRTM }\end{array}$ & \multirow{3}{*}{ RMS in $\mathrm{X}$ and $\mathrm{Y}$} \\
\hline & IRS-P6 Resourcesat-1 & 30 & DTED Level 1 data for areas up to $60^{\circ}$ latitude. ASTER GDEM for & \\
\hline & IRS-R2 Resourcesat-2 & 30 & $\begin{array}{l}\text { areas above } 60 \text { latitude. More accurate DEMs may be provided } \\
\text { from Cartosat-1 stereo pairs. }\end{array}$ & \\
\hline & \multirow[b]{2}{*}{ GeoEye, IKONOS } & GP & GeoProfessional product (--> orthorectified i.e. terrain corrected) & \multirow[b]{2}{*}{ no } \\
\hline & & PP & $\begin{array}{l}\text { GeoProfessionalPrecision product (--> option is available for } \\
\text { GeoProfessional products. GCPs are needed to increase accuracy) }\end{array}$ & \\
\hline & \multirow{3}{*}{ QuickBird, WorldView2 } & $\mathrm{PD}$ & Ortho Vision Premium Display & \multirow{3}{*}{ no } \\
\hline & & VD & Ortho Vision Display - default & \\
\hline & & OR & Ortho Custom Ortho (customer supplied support data) & \\
\hline & \multirow{6}{*}{ WorldView1 } & PP & Ortho Vision Premium Precision & \multirow{6}{*}{ tno } \\
\hline & & PM & Ortho Vision Premium Mapping & \\
\hline & & $\mathrm{VP}$ & Ortho Vision Precision & \\
\hline & & $\mathrm{VM}$ & Ortho Vision Mapping & \\
\hline & & ST & Ortho Ready Standard Stereo Imagery & \\
\hline & & OR & Ortho Custom Ortho (customer supplied support data) & \\
\hline & RapidEye & $3 \mathrm{~A}$ & $\begin{array}{l}\text { Based on sensor telemetry and sensor model for correction of sensor } \\
\text { related effects; Attitude telemetry and ephemeris for correction of } \\
\text { spacecraft; GCPs for refinement; SRTM3 DEM and better. }\end{array}$ & no \\
\hline & SPOT-5/6/7, & 3 & $\begin{array}{l}\text { RCP model. Global DEM (SRTM, R3D ...) or DEM from stereo } \\
\text { pairs or specific. Others algorithms are proprietary. }\end{array}$ & $\begin{array}{l}\text { SP6/7 only Plani- } \\
\text { metric accuracy } \\
\text { CE68, CE90 }\end{array}$ \\
\hline & Pléiades 1A/B & 3 or ORT & $\begin{array}{l}\text { RCP model. Global DEM (SRTM, R3D...) or DEM from stereo } \\
\text { pairs or specific. Others algorithms are proprietary. }\end{array}$ & $\begin{array}{l}\text { Planimetric } \\
\text { accuracy CE68, } \\
\text { CE90 }\end{array}$ \\
\hline
\end{tabular}

Table 1. Definitions of Processing Level Code, processes and geometric errors across the CCMEs.

processes, geometric errors are listed. Note that this table reflects the current Authors' understanding and may not contain some elements which the CCMEs should like to see included. Even though

Table 1 is neither meant to convert definitions into one another nor to identify any "best option" among many, it offers an overview at a glance of the diversities among the different CCMEs. A collection of differences is the baseline to compare them and discover similarities. Potentially, a common geolocation policy can be inferred and eventually proposed. 


\section{REPORTING CLOUD MEASURES}

For certain projects in Copernicus services (e.g. CORE projects) a maximum cloud coverage allowed for the delivered imagery is contractually defined. These maximum limits, defined in DWH (2014) under REQ-5.3.3-6 Cloud Cover and Haze, are different depending on the climatic zones illustarted in Figure 1. The following three zones are identified for Europe:

- Zone A (cloudiest): $20 \%$ max

- Zone B (cloud prone): $10 \% \max$

- Zones C/D (limited cloud): 5\% max

Even though not contractually required also cloud shadows, smoke and contrails may be relevant for the user. In some cases also the location of clouds may be relevant: e.g. some land cover mapping projects may be unaffected by the clouds over the sea.

Given these contractual and technical requirements for cloud coverage it is important to define a commonly agreed method to detect cloudy/hazy pixels and a common unit (percentage?) to express this metric in the metadata.
Table 2 collects, across Copernicus optical missions, the information reported in the product metadata, in the users' manual, in the cloud mask (if available) and other information relevant to clouds.

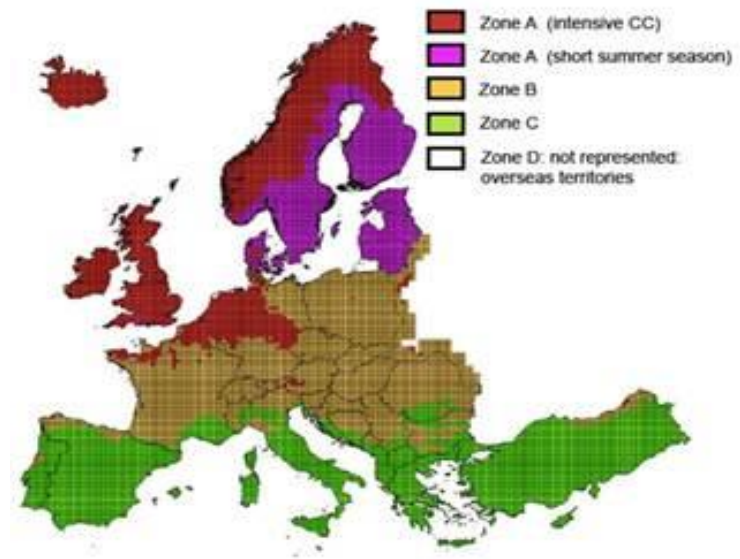

Figure 1. Zone map of maximum accepted cloud / haze coverage in Europe (from DWH, 2014).

\begin{tabular}{|c|c|c|c|c|}
\hline Mission & $\begin{array}{l}\text { Value reported in } \\
\text { metadata }\end{array}$ & Description from Product Manual & $\begin{array}{l}\text { Cloud } \\
\text { Mask } \\
\end{array}$ & Other than Cloud \\
\hline Deimos-1 & \multirow{2}{*}{ No } & \multirow{2}{*}{$\begin{array}{l}\text { No mention of any masks in the } \\
\text { product manuals }\end{array}$} & \multirow{2}{*}{ No } & \multirow[t]{2}{*}{ No cloud shadow } \\
\hline DMC constellation & & & & \\
\hline IKONOS & $\begin{array}{l}\text { Reported in } 2 \text { spots: } \\
\text { "\% cloud cover" and } \\
\text { "\% component cloud } \\
\text { cover" }\end{array}$ & \multirow[t]{2}{*}{$\begin{array}{l}\text { Product manual for IKONOS and } \\
\text { GeoEye say cloud \% reported for all } \\
\text { products except level s } 5 \text { and } 7\end{array}$} & \multirow[t]{2}{*}{ No } & \multirow[t]{2}{*}{ N/A } \\
\hline GeoEye & Yes, percentage & & & \\
\hline QuickBird & $\begin{array}{l}\text { Yes, fraction. } 999 \text { if } \\
\text { not assessed. }\end{array}$ & $\begin{array}{l}\text { A definite boundary between the } \\
\text { affected pixels and the unaffected } \\
\text { pixels must be visible. Assessment } \\
\text { based on either AOI or whole scene } \\
\text { depending on the order. }\end{array}$ & \multirow[t]{2}{*}{$\begin{array}{l}\text { provided } \\
\text { on request }\end{array}$} & \multirow[t]{2}{*}{ No cloud shadow } \\
\hline WorldView1/2 & Yes, exponential & $\begin{array}{l}\text { Simple comment saying that an } \\
\text { automated CCA tool is used }\end{array}$ & & \\
\hline RapidEye & Yes, percentage & $\begin{array}{l}\text { Automatic tool provides Unusable } \\
\text { Data Mask (UDM). Product includes } \\
\text { clouds. Visual inspection assessment } \\
\text { for errors due to inclusion of snow/ice/ } \\
\text { bright surfaces). Darker or popcorn } \\
\text { clouds may be undetected. }\end{array}$ & $\begin{array}{l}\text { Yes, in } \\
\text { TIFF }\end{array}$ & No haze/cloud shadow \\
\hline PROBA-V & Yes, percentage & $\begin{array}{l}\text { Clouds mapped by } 12 \text { s difference b/w } \\
\text { NIR and SWIR. Cloud mask derived } \\
\text { from SPOT-VGT (Lissens et al. 2000) }\end{array}$ & $\begin{array}{l}\text { Derived } \\
\text { from } \\
\text { SPOT- } \\
\text { VGT } \\
\end{array}$ & $\begin{array}{l}\text { Indicators for clear, cloud, } \\
\text { ice, shadows and } \\
\text { undefined. }\end{array}$ \\
\hline ResourceSat-1/2 & No & No mention of methods & Yes & $\begin{array}{l}\text { Manual judgement in } \\
10 \% \text { steps per quarter } \\
\text { scene (unshifted) } \\
\end{array}$ \\
\hline Pléiades 1A/1B & No & Cloud Vector Mask provided, filename & $\begin{array}{l}\text { Yes, in } \\
\text { GML }\end{array}$ & $\begin{array}{l}\text { Automatically estimated } \\
\text { with radiometric and } \\
\text { geometric models. }\end{array}$ \\
\hline SPOT6 & & & format & $\begin{array}{l}\text { Manually corrected and } \\
\text { snow masks added. }\end{array}$ \\
\hline SPOT5 & No & No mention & No & No \\
\hline
\end{tabular}

Table 2. Cloud information reported in different sources (metadata, users' manual, masks). 


\section{ACQUISITION MODE NAMING}

Optical data may have various acquisition modes depending on the sensor spectral arrangements. In addition, different algorithms can be applied to generate different products. For example a multispectral sensor and a panchromatic sensor may be delivered together in one product package commonly called "Bundle". In turn, the two single products included in a Bundle (i.e. the multispectral and the Panchromatic), if processed together, generate another product called "Pansharpened" which may be composed of three or four bands. Therefore, depending on their composition, the different product packages delivered to the market must have various product names and product codes across the CCMs.

Table 3 reports an example of this situation just for the Multispectral products. The CQC Team is working on similar matrices also for other product categories such as Pansharpened, Panchromatic and Bundle. The second column
(CCM Name -Acq.Mode) lists the acquisition mode codes used by the CCMs to identify their multispectral products, whereas their relevant description is reported in the third column.

The convention suggested in Copernicus groups the many names within a category using one descriptive name. Furthermore, the use of acronyms is minimised (e.g. Multispectral instead of MS)

The aim of this comparison matrix is not to uniform all code names in one name because the codes are part of configuration files which control many automatic processes in the CCM facilities. As these impact on the overall Copernicus system the different Acquisition Modes are not expected to be renamed easily within the CCM internal systems. The names suggested here are just intended to be part of an intuitive language which can be used in the context of Copernicus tools and web interfaces.

\begin{tabular}{|c|c|c|c|}
\hline Mission & $\begin{array}{l}\text { CCM Name } \\
\text {-Acq.Mode }\end{array}$ & CCM Description & $\begin{array}{l}\text { Copernicus } \\
\text { suggested Name }\end{array}$ \\
\hline $\begin{array}{l}\text { IRS-P6 } \\
\text { Resourcesat-1 }\end{array}$ & M_ & Mono Mode, browse product & \multirow{2}{*}{ Multispectral 1 band } \\
\hline $\begin{array}{l}\text { IRS-R2 } \\
\text { Resourcesat-2 }\end{array}$ & M_ & Mono Mode, browse product & \\
\hline Deimos-1 & SL6_22S & Surrey Linear Imager - 6 Channels - 22 metre - Secondary Bank & \multirow{3}{*}{ Multispectral 3 bands } \\
\hline $\begin{array}{l}\text { DMC } \\
\text { Constellation }\end{array}$ & SL6_32P & Surrey Linear Imager - 6 Channels - 32 metre - Primary Bank & \\
\hline SPOT-4 & HRV_X & Multi-Spectral SPOT $420 \mathrm{~m} 3$ bands & \\
\hline GeoEye-1 & MS4 & 4 Multispectral files only & \multirow{14}{*}{ Multispectral 4 bands } \\
\hline IKONOS-2 & MS4 & 4 Multispectral files only & \\
\hline $\begin{array}{l}\text { IRS-P6 } \\
\text { Resourcesat-1 }\end{array}$ & $X_{-}$ & $\begin{array}{l}\text { Multispectral Mode, stiched image from sensors 'A' \& 'B', browse } \\
\text { product }\end{array}$ & \\
\hline $\begin{array}{l}\text { IRS-R2 } \\
\text { Resourcesat-2 }\end{array}$ & $X_{-}$ & $\begin{array}{l}\text { Multispectral Mode, stiched image from sensors 'A' \& 'B', browse } \\
\text { product }\end{array}$ & \\
\hline SPOT-4 & HIR_I__ & Multi-Spectral SPOT $420 \mathrm{~m} 4$ bands & \\
\hline SPOT-5 & HRG_J__ & Multi-spectral SPOT $510 \mathrm{~m} 4$ bands & \\
\hline SPOT-6/7 & MS & Multi-spectral SPOT $66 \mathrm{~m} 4$ bands & \\
\hline KOMPSAT2 & MSC_MS_ & Multi-spectral & \\
\hline Pleiades 1A/1B & MS & Multi-spectral & \\
\hline FORMOSAT2 & RSI_MS_ & Multi-spectral & \\
\hline PROBA-V & VGT_P_C & VGT P Center camera & \\
\hline PROBA-V & VG2_D10 & VG2_D10 & \\
\hline QuickBird-2 & BGI_MS4 & 4 Multispectral files only & \\
\hline WorldView-2 & WV1_MS4 & 4 Multispectral files only & \\
\hline RapidEye & MSI_IMG & 5-Bands Multi Spectral Imager & Multispectral 5 bands \\
\hline WorldView-2 & WV1_MS8 & 8 Multispectral files only & Multispectral 8 bands \\
\hline
\end{tabular}

Table 3. Comparison of multispectral product names/codes across different CCMs.

\section{DEFINITIONS OF ACQUISITION ANGLES}

The Acquisition angle is another disputed topic in some Copernicus services, especially among the Emergency users. Its definition refers actually to at least two angles: the Viewing angle and the Incidence angle. The former one is the angle from the instrument point of view. It represents the angle between the look direction from the satellite and nadir and combines the platform pitch and roll angles. For this reason it is sometimes called also "combined angle". The latter, Incidence Angle, is also widely used in the literature.

Figure 2 illustrates the concepts of viewing and incidence angles. 


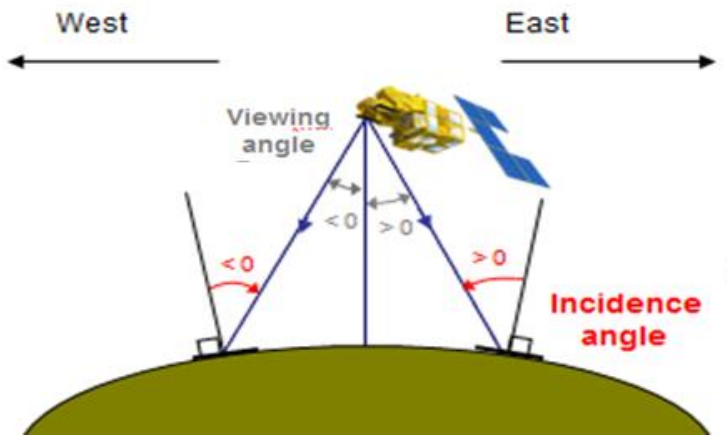

Figure 2. Representation of Viewing and Incidence angles (Courtesy of ASTRIUM DS France).

Table 4 lists the acquisition angles found in various scientific sources and in the literature documentation.

\begin{tabular}{|l|l|}
\hline Angle name & Source \\
\hline Acquisition & Generic \\
\hline Collection & Term mainly used for e-GEOS products \\
\hline Off nadir & Generic, referred to Viewing angle \\
\hline Viewing & $\begin{array}{l}\text { See } \\
\text { Figure 2 }\end{array}$ \\
\hline Incidence & $\begin{array}{l}\text { See } \\
\text { Figure 2 }\end{array}$ \\
\hline Combined & $\begin{array}{l}\text { Referred as Viewing angle. Term mainly } \\
\text { used for ASTRIUM DS France products. }\end{array}$ \\
\hline Look angle & Many Copernicus services and tools \\
\hline
\end{tabular}

Table 4. Definitions of acquisition angles from various sources.

\section{CONCLUSIONS}

The CQC harmonisation task seeks to ensure coordination to facilitate EO data consistency and interoperability across Copernicus communities and for the benefit of all stakeholders. Some of the organisations and international initiatives discussed in this paper may themselves be considered by broader EO representative communities as reference for "best practices" but would always be seen as living processes or documents that could, with time, be improved upon.

Unlike the organisations responsible for enforcing the best practice rules already in place in the EO community, the CQC task is not to create further standards or rules. It will provide support, guidance and, when relevant, capacity building towards the international quality framework already in place to facilitate harmonisation and interoperability of EO data, products and tools.

The issues presented in this paper refer only to some of the areas of inconstancies (e.g. processing levels, cloud measures, naming conventions and angles definitions) which characterize the CCMs and need to be harmonised. In general, the approach implemented by CQC for these and other harmonisation issues is strongly based on the rich legacy of European and international standards (e.g. INSPIRE, OGC, QA4EO) which just need to be implemented to uphold the interest of the overall Copernicus community and the commercial appeal of EO products and services.

\section{REFERENCES}

Eriksson, H. and Hartnor, J., 2006. Data harmonisation requirements (RISE project). Available from: http://www.eurogeographics.org/eng/documents/RISE13_Data_ Harmonisation_Requirements_v1.0.pdf [Accessed 20 April 2011].

GEO. A Quality Assurance Framework for Earth Observation: Principles. http://qa4eo.org/docs/QA4EO_Principles_v4.0.pdf 2010 [accessed 16 March 2015].

Giger C. and Schulze Althoff J. INSPIRE Anforderungen an Netzwerkdienste Unterschiede zu Vorgaben an Dienste in der Schweiz. Giger GeoIT (2012)

OGC: Open Geospatial Consortium Inc. OGC® Catalogue Services Standard 2.0 Extension Package for ebRIM Application Profile: Earth Observation Products. (2010)

Tikunov, V.S., Ormeling, F., and Konecny, M., 2008. Atlas information systems and geographical names information systems as contributants to spatial data infrastructure. International Journal of Digital Earth, 1 (3), 279_290.

Gore, A., 1999. The digital earth: understanding our planet in the 21 st century. Photogrammetric Engineering and Remote Sensing, 65 (5), 528.

Grossner, K., Goodchild, M.F., and Clarke, K., 2008. Defining a digital earth system.Transactions in GIS, 12 (1), 145_160.

Hall, M., 2006. HarmonISA Land-Use viewer system: system documentation and handbook. HarmonISA. Available from: http://harmonisa.uni-klu.ac.at/

INSPIRE online literature:

- Website: http://inspire-geoportal.ec.europa.eu/

- Guidelines:http://eurlex.europa.eu/LexUriServ/LexUriServ.do?uri=OJ:L:2007:108 :0001:0014:DE:PDF

- Metadata: //MD_IR_and_ISO_20090218[1]3219435009/MD_IR and_ISO_20090218[1].pdf

- Thematic Working Group Administrative units: http://inspire.jrc.ec.europa.eu/documents/Data_Specifications/ INSPIRE_DataSpecification_AU_v3.0.1.pdf

- Thematic Working Group Cadastral Parcels: http://inspire.jrc.ec.europa.eu/documents/Data_Specifications/ INSPIRE_DataSpecification_CP_v3.0.1.pdf

Kuijper A. Transitions of a multi-scale hierarchical image descriptor, Second International Conference on Scale Space Methods and Variational Methods in Computer Vision (SSVM09, Voss, Norway, June 1 - June 5, 2009). LNCS 5567 pp. 844--855, 2009.

McKee, L., 2001. OGC's role in the spatial standards world. Technical report. Available from: http://portal.opengeospatial.org/files/index.php?artifact_id6207 \&version $1 \&$ formatpdf

Portele, C., 2006. Methodology \& guidelines on use case and schema development (RISE project). Available from: http://www.eurogeographics.org/documents/RISE15Methodolo gyandGuidelinesV1.2.pdf 
Villa, P., Gomarasca, M.A., and Reitz, T., 2008. HUMBOLDT project for data harmonization in the framework of GMES and ESDI: introduction and early achievements. International Archives of the Photogrammetry, Remote Sensing and Spatial Information Sciences, XXXVII (B4), 1741_1746.

Paolo Villa, Roderic Molina, Mario A. Gomarasca \& Emanuele Roccatagliata (2012) Harmonisation requirements and capabilities towards a European spatial data infrastructure (ESDI): the HUMBOLDT protected areas scenario, International Journal of Digital Earth, 5:5, 417-438, DOI: 10.1080/17538947.2011.585183.
Ziegler, P. and Dittrich, K.R., 2004. Three decades of data integration all problems solved? In: IFIP congress topical sessions, building the information society, IFIP 18th world computer congress, topical sessions, 2227 August 2004, Toulouse, France, Kluwer, 312. 438 P.

DWH (2014) - EUROPEAN COMMISSION - Data Warehouse Requirements -Version 2.0 Copernicus Data Access Specifications of the space-based Earth Observation needs for the period 2014-2020 